The Behavior of Same-Race Others and its Effects on Black Patients' Attention to Publicly Presented HIV-Prevention Information

Neil A. Lewis, Jr.'2, Daniel G. Kougias ${ }^{3}$, Koji J. Takahashi ${ }^{4}$, \& Allison Earl ${ }^{4}$

Cornell University

${ }^{2}$ Weill Cornell Medical College

${ }^{3}$ University of Illinois at Urbana - Champaign

${ }^{4}$ University of Michigan

RUNNING HEAD: RACE, CONTEXT, AND ATTENTION TO HEALTH INFORMATION

Page Count: 28

Author Note:

Neil Lewis, Jr., Department of Communication, Cornell University and Division of General

Internal Medicine, Weill Cornell Medical College.

Daniel Kougias, Neuroscience Program University of Illinois at Urbana - Champaign

Koji Takahashi and Allison Earl, Department of Psychology, Institute for Social Research, Research Center for Group Dynamics, University of Michigan.

Correspondence concerning this manuscript may be addressed to Neil Lewis, Jr

(nlewisjr@cornell.edu) or Allison Earl (anearl@umich.edu). 


\begin{abstract}
Black Americans make up 13\% of the U.S. population (U.S. Census Bureau, 2010), yet account for 54\% of HIV deaths (CDC, 2013) and 44\% of new HIV diagnoses (CDC, 2015). Why do Black Americans die from HIV at such a disproportionate rate? In the current study, we asked whether the presence and behavior of in-group peers in public health settings may influence Black Americans' attention to HIV information, given the racialized nature of HIV-stigma in Black American communities (Cohen, 1999). In a quasi-experimental field study conducted in a public health clinic $(\mathrm{N}=260)$, we found that Black patients were less likely to pay attention to HIV-prevention information in the presence of other Black patients, unless those patients were also paying attention to the information. In contrast, Black patients' attention was unaffected by the presence of White patients. We end by discussing the implications of these findings for health communication theories and health practice geared toward reducing racial-health disparities in the United States.
\end{abstract}

Keywords: Selective Attention, Identity-based Motivation, Health Disparities, HIV 


\section{The Behavior of Same-Race Others and its Effects on Black Patients' Attention to Publicly Presented HIV-Prevention Information}

Black Americans make up 13\% of the U.S. population (US Census Bureau, 2010), yet account for 54\% of HIV deaths (Centers for Disease Control and Prevention [CDC], 2013) and $44 \%$ of new HIV diagnoses (CDC, 2015). These dismal statistics are surprising because the majority of Black Americans have long sought out HIV-prevention information (Kaiser Family Foundation, 1998), and researchers and practitioners have designed and implemented myriad HIV-prevention interventions in attempts to reduce these disparities (Albarracin, Wilson, Durantini, Sunderrajan, \& Livingood, 2016; Myint-U et al., 2008; Resnicow, Dilorio, \& Davis, 2008).

Although effective under tightly-controlled experimental trials, once HIV-prevention interventions are released into the community, their efficacy depends on how much attention target audiences pay to the messages (Earl, Albarracin, Durantini, Gunnoe, Leeper, \& Levitt, 2009; Earl, Crause, Vaid, \& Albarracin, 2016). For instance, once the incentives accompanying enrollment in an intervention program are removed, audiences may be less likely to attend to relevant information, particularly if that information is scary or stigmatizing. These findings are consistent with previous literature on selective exposure and attention (Knobloch-Westerwick, 2015; Slater, 2004) that posits that audiences who already agree with the arguments outlined in a message, or who are already engaging in the prevention behaviors advocated by an intervention are more likely to seek out (Earl et al., 2009) and pay attention to messages (Earl et al., 2016) than audiences for whom the recommendations are inconsistent with current attitudes and behaviors (see also, Lewis \& Oyserman, 2016). These findings are problematic, as they may further exacerbate health disparities. 
There is evidence suggesting information processes biases may partially contribute to racial inequities in HIV outcomes. For example, in two field studies conducted in public health clinics, Earl and colleagues (2016) found across multiple measures of attention, that Black patients paid less attention to HIV information than their White counterparts, which yielded less access to certain health information for Black than White patients.

Those findings led us to ask: why would people ignore health information that could save their lives? One potential reason is that, in naturalistic contexts, norms about how one behaves in a situation may take over (Lapinski, Maloney, \& Shulman, 2013) and influence motives to regulate self-concept and behaviors (Knobloch-Westerwick, 2015). In particular, individuals may perceive what is socially appropriate or not based on the behavior of others (Cialdini, Kallgren, \& Reno, 1991; Hogg \& Tindale, 2005; Lapinski \& Real, 2005), and act according to those norms (Fishbein \& Ajzen, 2011; Oyserman, Lewis, Yan, Fisher, O’Donnell, \& Horowitz, 2017).

A normative account of attention to HIV information would suggests that all people should ignore HIV information, yet Black patients ignore HIV information at greater rates than their White counterparts (Earl et al., 2016). Why might that be? One possibility is that there are different norms about attention to HIV information among Black and White Americans, leading to divergent social consequences for paying attention to HIV information for Black Americans than other groups (see Cohen, 1999; Knobloch-Westerwick, 2015; Rimal, Lapinski, Turner, \& Smith, 2011). This is because, for a host of complex historical reasons, HIV is particularly stigmatized within Black American communities compared to other communities in the United States (Brooks, Etzel, Hinojos, Henry, \& Perez, 2005; Cohen, 1999; Galvan, Davis, Banks, \& Bing, 2008). In this case, norms about attention to HIV prevention information may be modulated by group identity (Lapinski \& Rimal, 2005; Rimal \& Real, 2005). However, for 
norms to impact behavior, people need to feel affinity (similarity) or to desire connections (aspiration) with the reference groups (Rimal \& Real, 2005). In the case of attention to HIV prevention information, it is unclear whether Black Americans would be more impacted by the behavior of similar others (Black Americans; Oyserman \& Lewis, 2017) or dissimilar others (White Americans; Hurd, Sellers, Cogburn, Butler-Barnes, \& Zimmerman, 2013).

On the one hand, Black Americans may be more influenced by similar others, such as other Black Americans. In this case, because of stigma-laden views of HIV within Black American communities (Brooks et al., 2005; Cohen, 1999; Galvin et al., 2008), it seems plausible that Black Americans may avoid paying attention to HIV information in settings where other members of their racial-ethnic group are present and behaving in ways that highlight group-based stigma concerns. This would occur because racial-ethnic identity serves as a lens through which people make sense of themselves and the world around them (Huang \& Shen, 2016; Oyserman, Brickman, \& Rhodes, 2007; Oyserman \& Harrison, 1998; Oyserman \& Lewis, 2017), and one core component of Black racial identity is a sense of connection with other Black people (Oyserman, Gant, \& Ager, 1995; Oyserman \& Lewis, 2017). Therefore, engaging in any behavior that would threaten a sense of connection to the community, like paying attention to HIV information -- information about a condition deeply stigmatized by the group -- would be self-threatening for Black Americans, and thus Black Americans should be less likely to engage in those behaviors (Albarracin, Durantini, \& Earl, 2006; Oyserman \& Fisher, 2017).

On the other hand, Black Americans may be more influenced by dissimilar others, such as White Americans. In this case, Black Americans may ignore publicly presented HIV information because of the potential signals it may send to out-group rather than in-group members. In addition to sense of connection with other Black Americans (Oyserman et al., 
1995), another component of Black racial identity is awareness of racism and rejection of negative racial stereotypes (Hughes, Kiecolt, Keith, \& Demo, 2015; Hurd et al., 2013). From that perspective, it seems plausible that due to historical patterns of racial stereotyping in the United States by Whites, Black Americans might have the greatest concerns about confirming negative stereotypes (e.g., about Blacks having HIV) when they are in majority White spaces; those may be the conditions under which Black patients ignore HIV information (see also Lewis \& Oyserman, 2016; Lewis \& Sekaquaptewa, 2016; Oyserman \& Fisher, 2017).

Either process - avoiding stigmatization from in-group members or avoiding being negatively stereotyped by out-group members - would lead to disengagement from publicly presented HIV information (Earl et al., 2009, 2016). At present, it is unclear whose presence or behavior evokes the stigma concerns and subsequent disengagement found in previous studies (Earl et al., 2015). It could be the presence of outgroup or ingroup members, or something about the way people are behaving in the setting that influences the behaviors of target audiences (Hogg \& Tindale, 2005). Identifying which factors modulate attention is important for both theory and interventions to reduce disparities in outcomes (Earl \& Lewis, 2019; Lewin, 1946).

\section{Current Study}

The goal of the current study is to examine how the presence and behavior of different people influence Black patients' attention to publicly presented health information. Understanding these dynamics will give us a better understanding of the paradox of Black community members wanting (Kaiser Family Foundation, 1998) but not paying attention to (Earl et al., 2016) HIV-prevention information, as well as insights about how to address it. Overall, our goal is to examine three related research questions: 
Research Question 1: Does the presence of out-group members decrease Black patients' attention to publicly presented HIV-prevention information?

Research Question 2: Does the presence of in-group members decrease Black patients' attention to publicly presented HIV-prevention information?

Research Question 3: Does the behavior of in-group or out-group members influence Black patients' attention to publicly presented HIV-prevention information?

\section{Method}

To answer these questions, we conducted a quasi-randomized trial in the waiting room of a public health clinic. We partnered with the clinic directors to randomly assign health messages to be played in the clinic waiting room on a day and time schedule and observed patients' attention to the messages. This design allows us to examine how attention processes unfold naturalistically in health clinics, with all of the complexities of audience attention, multi-step flow, and community processes intact (Slater, 2004). Specifically, our quasi-experimental design allows us to examine the dual influence of health messages and live in vivo audiences on Black patients' attention to publicly presented health information. This study was approved by the institutional review board at the University of Illinois Urbana-Champaign.

Participants and design. Participants were 260 clients of a public health clinic in the Midwestern United States, and were demographically diverse (122 men, 138 women; 111 Black Americans, 128 White Americans, 21 “Other")'. The study design was a 2 (Observer perception of patient race: Black vs. White) ${ }^{2} \mathrm{X} 2$ (Message type: HIV-prevention vs. flu-prevention) X

\footnotetext{
${ }^{1}$ Because the study was designed to examine health disparities between Black and White Americans, participants of other races (e.g., Asian Americans) $(n=21)$ were not included as targets in the analyses, but were coded as "other race" audience members.

2 Pilot testing with 41 clients confirmed that observer perception of patient race and participant's self-reported race are highly related $\left(\chi^{2}=41.00, p<.001\right)$.
} 
continuous (Number of others in the waiting room) design with covariates (duration of time in the waiting room and baseline alertness).

Procedure. Participants were unobtrusively observed while they visited the health clinic. During this time, participants had the opportunity to watch a video about HIV - or fluprevention. Both videos were standard-of-care at the health clinic, however, which video played was controlled by the research team and randomized by day. Our coder recorded the amount of attention paid to the video for the entirety of their time in the waiting room, as well as demographic variables and features of the visit, including participant alertness and time spent in the waiting room, and demographic composition of other participants in the waiting room (see Supplemental materials Section S1 for details).

Videos. Both videos were extensively piloted to ensure comparability on a number of dimensions known to impact attention to health information, including relevance, importance, and novelty (Earl et al., 2016). The research team did not develop or have control over the specific content of the videos; we chose from a set of messages that were approved by the Department of Health for display in that health clinic.

HIV-Prevention Video. The HIV-prevention video, "Safe in the City," is a soap-opera style video about HIV- and STI-prevention, that was designed using insights from research on deep tailoring (see Huang \& Shen, 2016) to be culturally resonant to Black Americans (see Myint-U et al., 2008 for details on message content development and testing). In particular, the video featured characters and plot lines that were pilot tested to resonate with target audiences. For instance, in one story, Paul and Jasmine are in a new relationship, but Paul has a sexual encounter with an ex-girlfriend. Paul and Jasmine have to negotiate condom use and testing for sexually transmitted infections in the context of their new relationship. Focus groups gave 
feedback to make the video seem diverse and inclusive (Myint-U et al., 2008). The video was approximately twenty minutes long and ran on a continuous loop in the waiting room.

Flu-Prevention Video. The flu-prevention video, "Germ Busters," discussed prevention, symptomology, and treatment of the flu, including H1N1. The video was approximately twenty minutes long and ran on a continuous loop in the waiting room.

Unobtrusive Observation and Behavioral Coding. One White senior research assistant, who was extensively trained, did behavioral coding . Behavioral coding consisted not only of the target behavior (attention to the video) but also included coding of other behaviors relevant to attention in the waiting room (e.g., brochures read or online information search). Unfortunately, low base rates of attention to other types of information precluded inclusion in the present report. In addition, the coder recorded perceived race as a primary variable of interest derived from previous work (Earl et al., 2016), but also coded other demographic markers (e.g., gender, weight status, presence of tattoos, etc.). The rationale for inclusion of these additional measures was to obscure the primary research questions of interest by having the coder focus on many features of audience members, rather than just race. Once the coder was able to consistently agree with the principle research staff after multiple rounds of coder training $(x>0.80)$, the study commenced. See supplemental materials for the coding sheet.

Attention. Because of the nature of unobtrusive observation as a method, a holistic measure of attention was selected as the primary dependent measure. Although the research team would have preferred to video record the waiting room to measure correspondence of attention with our variables of interest in a more fine-grained way, the health department that oversees the

${ }^{3}$ Although the coder was privy to the content of the videos being played, the coder had no knowledge of the specific research questions. 
clinic denied the request because of concerns that clients may fail to return to the clinic if they felt like their behavior was being recorded. Thus, the coding sheet included a three-level measure of attention (0 ignoring the video, 1 casually looking/glancing at the video, and 2 paying attention to the video). This measure of attention was validated by previous health communication research, which found that coders' observation of participants' attention using this measure predicted participants' self-reported attention, interest, motivation to attend to the information, message recall, and performance on a post-exposure multiple-choice recognition quiz (Albarracin, Leeper, Earl, \& Durantini, 2008; Bruder, Albarracin, \& Earl., 2008).

Participant Demographics and Situational Features. The coding sheet also included demographic information about the participants and features of the situation. Baseline level of alertness was operationalized as a holistic assessment of participants' alertness and ranged from 1 extremely bored/tired to 7 extremely alert/agitated. Baseline alertness was normally distributed, with most participants receiving an alertness score of 4 , average alertness $\left(M_{\text {aletress }}=\right.$ $3.90, S D_{\text {alcrness }}=1.02$ ). Duration was assessed by measuring the total amount of time participants were in the waiting room and ranged from $1-95$ minutes $\left(M_{\text {duration }}=18.29, S D_{\text {duration }}=14.05\right)$.

Other People Present. The audience was coded by totaling the number of other clients (and their demographics) who were in the waiting room at the same time as a target client. We coded other people from the perspective of the target, so the coder, and their corresponding demographic information, were also included in the calculation of other people present.

\section{Analytic Strategy}

We used a series of linear mixed-effects models in which individuals were nested within day of observation (treated as a random factor). Information type (HIV vs. Flu), observer perception of patient race (Black vs. White), and Presence of other people (continuous variable) 
were treated as fixed factors; in addition, participants' baseline level of alertness and duration in the waiting room were treated as covariates. We estimated models using restricted maximum likelihood (REML). For significance tests, we estimated degrees of freedom with the Satterthwaite's approximation, which corrects for heterogeneity of variance. All analyses were conducted in R using the lme4 package (Bates, Machler, Bolker, \& Walker, 2015).

\section{Results}

\section{RQ1: Does the presence of out-group members decrease Black patients' attention to} publicly presented HIV-prevention information? We examined effects of perceived race (Black vs. White), information type (HIV-vs flu-prevention), presence of outgroup members, and their interactions on all participants' attention to health information (see Table 1 in Supplemental Materials Section S2 for all coefficients). We found no main effects of participant race $F(1,213.57)=0.34, p=.563$, information type $F(1,9.68)=1.06, p=.329$, or presence of outgroup members $F(1,189.22)=1.17, p=.281$. There was a significant interaction between race and information type $F(1,212.35)=6.75, p=.010$, which was explained by increased attention to the HIV video among White patients $(b=0.40, p=.028)^{4}$ and no difference in attention among Black patients $(b=-0.12, p=.488)$. However, there were no two-way interactions between race and presence of outgroup members $F(1,217.04)=1.67, p=.198$, between information type and presence of outgroup members $F(1,181.54)=.45, p=.505$, and no three-way interaction $F(1,217.70)=1.77, p=.185$. These results suggest, no, it is not the presence of outgroup members that leads to the decreased attention among Black (or White) patients.

\footnotetext{
${ }^{4}$ Because this simple effect was not predicted and is unrelated to our central research questions, we opted to avoid overinterpreting it.
} 


\section{RQ2: Does the presence of in-group members decrease Black patients' attention to}

publicly presented HIV-prevention information? We examined effects of perceived race

(Black vs. White), information type (HIV- vs flu-prevention), presence of same-race others, and their interactions on attention to health information (see Table 2 in Supplemental Materials

Section S3 for all coefficients). We found no main effect of participant race $F(1,214.44)=0.27$, $p=.605$, information type $F(1,10.60)=0.01, p=.936$, or presence of same-race others $F(1$, 201.88) $=0.15, p=.695$ on attention. We did find a race by information type interaction $F(1$, $215.73)=10.53, p=.001$, and a presence of same race others by information type interaction $F(1,184.81)=6.13, p=.014$, but not a race by presence of same-race others interaction $F(1$, $209.35)=.34, p=.563$. We also found a significant three-way interaction $F(1,210.36)=8.86, p$ $=.003$ ). As illustrated in Figure 1, if a Black patient was the only person of their race in the clinic waiting room, they paid more attention to HIV compared to flu information (mean difference $=.56, p=.039)$. If a black patient was one of few (1-3) Black patients in the clinic waiting room, they paid approximately equal amounts of attention to the health information on display, regardless of whether it was HIV or flu information (mean differences between information type at low presence of same race others (1-3) were less than $.3, p s>.19)$. However, if there were many ( 4 or 5 ) other Black patients in clinic waiting room at the same time as a Black patient, they were significantly less likely to pay attention to the health information on display if it was HIV information than if it was flu information (mean differences between information type at high presence of same race others were $.52, p=.021$ when four others were present and $.78, p=.003$ when five others were present). As illustrated in Figure 2, White patients paid relatively little attention to the health information on display regardless of whether 
the information was HIV or flu information, and regardless of how many (1-11) same race others were in the clinic at the same time as them.

INSERT FIGURE 1 HERE

INSERT FIGURE 2 HERE

\section{RQ 3: Does the behavior of in-group members influence Black patients' attention to} publicly presented HIV-prevention information? We conducted one final analysis using the same linear-mixed effects modeling strategy as before, examining effects of perceived race (Black vs. White), information type (HIV- vs flu-prevention), ignoring behavior of Black patients, and their interactions on attention to health information (see Table 3 in Supplemental Materials for all coefficients). We found no main effect of race $F(1,228.51)=0.17, p=.680$, information type $F(1,10.00)=0.35, p=.567$, or ignoring behavior $F(1,207.45)=0.82, p=.368$. We also did not find a race by information type interaction $F(1,228.38)=2.81, p=.095$, a race by ignoring behavior interaction $F(1,228.45)=.54, p=.464$, or an information type by ignoring behavior interaction $F(1,204.85)=2.63, p=.106$. However, there was a significant three-way interaction $F(1,228.80)=8.32, p=.004)$. In general, as the number of Black patients who were ignoring information on display increased, patients themselves paid less attention to the message $(b=-.34, p=.004)$. This relationship was particularly pronounced for Black patients when HIV information was on display. As illustrated in Figure 3, if no other Black patients are ignoring the information, then a Black patient in the clinic is willing to pay a moderate amount of attention to 
the HIV message on display; by the time three Black patients are ignoring it however, attention drops to zeros.

\section{INSERT FIGURE 3 HERE}

\section{General Discussion}

\section{Summary of Findings}

We found that Black American patients' attention to health information was influenced by the type of health information being presented, as well as the presence and behavior of samerace others in a public health clinic waiting room. Specifically, when stigmatized HIVprevention information was playing in the waiting room, Black patients paid less attention to the information when other Black patients were present and ignoring the information, though paid moderate amounts of attention if other Black patients were not ignoring the information.

\section{Implications for Theory}

This work contributes to health communication theory on selective exposure (KnoblochWesterwick, 2015; Slater, 2004) and its implications for attention to health information and willingness to engage in health behaviors (Earl et al., 2009, 2015, 2016; Lewis \& Oyserman, 2016). This research has documented that norms that become salient in naturalistic contexts influence motives to regulate behaviors (Knobloch-Westerwick, 2015; Lapinski et al., 2013), and

\footnotetext{
${ }^{5}$ We also examined the attending behavior of other patients as the moderating variable (in contrast to ignoring behavior). That analysis is suggestive of a dose-response curve such that more Black patients paying the highest level of attention does increase attention for other Black patients. However, sample size constraints $(n=26)$ prohibit us from making strong claims about this. That is, only 26 Black patients paid the highest level of attention to the videos so we are hesitant to make strong claims based on so few people.
} 
those processes can explain why people avoid engaging with health information in the presence of some audiences but not others (Earl \& Albarracin, 2007; Earl et al., 2015, 2016; Lewis \& Oyserman, 2016). These normative influences can be quite powerful, and explain why even “deep tailoring” (Huang \& Shen, 2016) efforts like the HIV-prevention message used in the current study can be insufficient to capture the attention of target audiences. It is not just the message that matters, but also the audience in the room when the message is being watched (Lapinski et al., 2013) and attributes of the behaviors the researchers are trying to change (Rimal et al., 2011).

The current report suggests that identities (of both the message recipient and surrounding audiences) can have strong effects on selective approach or avoidance of messages, and one factor in particular that is relevant to consider is the impression being signaled particularly to members of the in-group (Hart, Richardson, Tortoriello, \& Earl, in press; Knobloch-Westerwick, 2015; Lewis \& Oyserman, 2016; Oyserman \& Fisher, 2017). Understanding these dynamic processes is important for understanding when and why health disparities emerge, as well as how to address them (Earl \& Lewis, 2019; Lewis \& Oyserman, 2016; Oyserman et al., 2017).

\section{Implications for Practice}

Our results suggest a potential intervention point to prevent disengagement from HIVprevention information by Black audiences. Specifically, we found that Black patients did not show reduced attention if the other Black patients in the waiting room were paying attention to the HIV-prevention video. This suggests that Black patients attend to social cues that can impact attending to stigmatized health information in the presence of other in-group others. One way to set norms without being able to control what other clients do in a waiting room may be to draw inspiration from work on parasocial media interactions, whereby audiences engage with media 
by forming connections with characters (Giles, 2002) or by incorporating strategies from twostep flow of communications models (Lazarsfeld, Berelson, \& Gaudet, 1944). In this way, audience engagement could be increased by having a pre-recorded video of similar others (“opinion leaders") reacting favorably to the video being viewed in tandem with the health message to structure norms about attending to HIV prevention information. Future research should test this possibility directly.

\section{Limitations, Constraints on Generality, and Final Note}

Like all studies, there are some limitations to our findings. First, with respect to sample, we purposefully focused on Black patients in the current study because of the theoretical implications of studying racial group differences in information processing biases (KnoblochWesterwick, 2015) and the practical implications of HIV disproportionately affecting Black Americans (CDC, 2013, 2015). The limitation of that decision is that we are unsure if our findings generalize to other groups who are also disproportionately affected by HIV but may have different concerns (e.g. Latinx Americans, Men who have sex with men, and the intersections thereof); until these results are replicated with other samples in other settings, we cannot be sure (Simons, Shoda, \& Lindsay, 2017). Second, with respect to the messages, we only used one set of videos in our study, videos that, due to variation in their deep tailoring approach, confounded information type and tailoring (it is worth noting that these were the ecologically valid standard of care videos for the clinic). Results may vary with messages constructed with different content.

Third, unobtrusive observation has strengths and weaknesses. On the one hand, unobtrusive observation is high in external validity, allowing access to how people actually 
behave in response to messages in the real world (Slater, 2004), while minimizing the effects of social desirability (Webb, Campbell, Schwartz, \& Sechrest, 1966). On the other hand, unobtrusive observation only captures overt, but not covert, attention to a health message. As such, demonstrating that participants do not overtly attend to information in a waiting room (e.g., observable behavior such as looking at a video) does not rule out the possibility that participants are covertly attending to information (e.g., listening to a video without directly looking at it). It is worth noting however, that this particular method of unobtrusive observation reliably predicts participants' self-reported attention, interest, motivation to attend to the information, message recall, and performance on a post-exposure multiple-choice recognition quiz (Albarracin et al., 2008; Bruder et al., 2008).

Fourth, although participants were not randomly assigned to conditions, information was quasi-randomized on a day-and-time schedule. Thus, although there are possible alternative explanations for why participants may engage or disengage attention with health communications in a public health clinic waiting room, what randomization allows for is a minimization of those alternative explanations to systematically influence our results. So, for instance, although one reason why audience members may not attend to health communications in a public health clinic waiting room is because they choose to talk with friends instead of attending to the message, whether or not clients arrive with a friend is unrelated to the study variables. Moreover, if the decision to talk to friends rather than attend to information does vary systematically (e.g., Black clients choose to talk to their friends more when the HIV versus flu video is in the room) that could be construed as additional evidence that Black audience members are more likely to disengage attention from HIV-prevention videos in the presence of other Black audience members. 
Despite these limitations, the current study contributes important insights to health communication theory and practice. Researchers, practitioners, and policy makers have spent decades developing interventions, leveraging insights on strategies like deep tailoring (Huang \& Shen, 2016) in attempts to address racial-ethnic disparities in health and health care (Bentacourt, Green, Carrillo, \& Ananeh-Firempong, 2003). These efforts should be applauded as they have advanced knowledge of how different target audiences respond to different health messages factors that are important to understand to develop effective interventions for reducing health disparities. To further advance this goal, we need to expand our understanding of the contextual processes that differentially impact behaviors in subgroups (Geronius et al., 2016; Lewis \& Oyserman, 2016; Oyserman \& Fisher, 2017). Understanding these behaviors, and the conditions under which they emerge, is critical for improving health and reducing disparities. 


\section{References}

Albarracin, D., Durantini, M. R., \& Earl, A. (2006). Empirical and theoretical conclusions of an analysis of outcomes of HIV-prevention interventions. Current Directions in Psychological Science, 15, 73-78.

Albarracin, D., Leeper, J., Earl, A., \& Durantini, M. R. (2008). From brochures to videos to counseling: Exposure to HIV-prevention programs. AIDS and Behavior, 12, 354-362.

Albarracin, D., Wilson, K., Durantini, M. R., Sunderrajan, A., \& Livingood, W. (2016). A metaintervention to increase completion of an HIV-prevention intervention: Results from a randomized controlled trial in the state of Florida. Journal of Consulting and Clinical Psychology, 84(12), 1052-1065.

Bates, D., Machler, M., Bolker, B., \& Walker, S. (2015). Fitting linear mixed-effects models using lm4. Journal of Statistical Software, 67(1), 1-48. doi:10.18637/jss.v067.i01

Bentacourt, J. R., Green, A. R., Carrillo, J. E., \& Ananeh-Firempong, O., II. (2003). Defining cultural competence: a practical framework for addressing racial/ethnic disparities in health and health care. Public Health Reports, 118, 293-302.

Brooks, R. A., Etzel, M. A., Hinojos, E., Henry, C. L., \& Perez, M. (2005). Preventing HIV among Latino and African American gay and bisexual men in a context of HIV-related stigma, discrimination, and homophobia: perspectives of providers. AIDS Patient Care \& STDS, 19(11), 737-744.

Bruder, L., Albarracin, D., \& Earl, A. (2008, March). Medical waiting rooms: Patients’ motivation, interest, and recall of educational materials. Poster presented at the annual meeting of the Southeastern Psychological Association, Charlotte, NC. 
Centers for Disease Control and Prevention. (2013). USA Causes of Death by Age and Gender. 2013; Retrieved from: http://www.worldlifeexpectancy.com/usa-cause-of-death-by-ageand-gender

Centers for Disease Control and Prevention. (2015). HIV Surveillance Report, Diagnoses of HIV Infection in the United States and Dependent Areas, 2015, Vol. 27; November 2016. Retrieved from:https://www.cdc.gov/hiv/pdf/library/reports/surveillance/ cdc-hivsurveillance-report-2015-vol-27.pdf

Cialdini, R. B., Kallgren, C. A., \& Reno, R. R. (1991). A focus theory of normative conduct: A theoretical refinement and reevaluation of the role of norms in human behavior. In Advances in experimental social psychology (Vol. 24, pp. 201-234). Academic Press.

Cohen, C. J. (1999). The boundaries of blackness: AIDS and the breakdown of black politics. Chicago, IL: University of Chicago Press.

Earl, A., \& Albarracin, D. (2007). Nature, decay, and spiraling of the effects of fear-inducing arguments and HIV counseling and testing: a meta-analysis of the short-and long-term outcomes of HIV-prevention interventions. Health Psychology, 26, 496-506.

Earl, A., Albarracin, D., Duraniti, M. R., Gunnoe, J. B., Leeper, J., \& Levvit, J. H. (2009). Participation in counseling programs: High-risk participants are reluctant to accept HIVprevention counseling. Journal of Consulting and Clinical Psychology, 77, 668-679.

Earl, A., Crause, C., Vaid, A., \& Albarracin, D. (2016). Disparities in attention to HIVprevention information. AIDS Care, 28, 79-86.

Earl, A., \& Lewis, N. A., Jr. (2019). Health in Context: New Perspectives on Healthy Thinking and Healthy Living. Journal of Experimental Social Psychology, 81(4), 1-4. 
Earl, A., Nisson, C., \& Albarracin, D. (2015). Stigma cues increase self-conscious emotions and decrease likelihood of attention to information about preventing stigmatized health issues. Acta de Investigacion Psicologica, 5, 1860-1871.

Fishbein, M., \& Ajzen, I. (2011). Predicting and changing behavior: The reasoned action approach. Psychology Press.

Galvan, F. H., Davis, E. M., Banks, D., \& Bing, E. G. (2008). HIV stigma and social support among African Americans. AIDS patient care and STDs, 22(5), 423-436.

Geronimus, A. T., James, S. A., Destin, M., Graham, L. F., Hatzenbuehler, M. L., Murphy, M. C., ...\& Thompson, J. P. (2016). Jedi public health: Co-creating an identity-safe culture to promote health equity. SSM-population health, 2, 105-116.

Giles, D. C. (2002). Parasocial interaction: A review of the literature and a model for future research. Media Psychology, 4, 279-305.

Hart, W. P., Richardson, K., Tortoriello, G., \& Earl, A. (in press). "You are what you read:” Is selective exposure people's way of telling us who they are? British Journal of Psychology

Hogg, M. A. and Tindale, S, (2005). Social identity, influence, and communication in small groups. Intergroup communication: Multiple perspectives. Edited by Jake Harwood and Howard Giles. New York, USA: Peter Lang.141-164.

Huang, Y., \& Shen, F. (2016). Effects of Cultural Tailoring on Persuasion in Cancer Communication: A Meta-Analysis. Journal of Communication, 66, 694-715.

Hughes, M., Kiecolt, K. J., Keith, V. M., \& Demo, D. H. (2015). Racial identity and well-being among African Americans. Social Psychology Quarterly, 78(1), 25-48. 
Hurd, N. M., Sellers, R. M., Cogburn, C. D., Butler-Barnes, S. T., \& Zimmerman, M. A. (2013). Racial identity and depressive symptoms among Black emerging adults. The moderating effects of neighborhood racial composition. Developmental Psychology, 49(5), 938-950.

Kaiser Family Foundation. (1998). African American and HIV/AIDS Survey. Retrieved from: http://www.kff.org/hivaids/african-american-and-hivaids-survey-news-release/

Knobloch-Westerwick, S. (2015). The Selective Exposure Self- and Affect-Management (SESAM) Model: Applications in the Realms of Race, Politics, and Health. Communication Research, 42(7), 959-985.

Lapinski, M. K., Maloney, E. K., Braz, M., \& Shulman, H. C. (2013). Testing the Effects of Social Norman and Behavioral Privacy on Hand Washing: A Field Experiment. Human Communication Research, 39, 21-46.

Lapinski, M. K., \& Rimal, R. N. (2005). An explication of social norms. Communication theory, 15(2), 127-147.

Lazarsfeld, P. F., Berelson, B., \& Gaudet, H. (1944). The People’s Choice. NY: Duell, Sloan \& Pearce.

Lewin, K. (1946). Action research and minority problems. Journal of Social Issues, 2(4), 34-46. Lewis, N. A., Jr., \& Oyserman, D. (2016). Using Identity-Based Motivation to Improve the Nation's Health Without Breaking the Bank. Behavioral Science \& Policy, 2(2), 25-38. Lewis, N. A., Jr., \& Sekaquaptewa, D. (2016). Beyond Test Performance: A Broader View of Stereotype Threat. Current Opinion in Psychology, 11, 40-43.

Myint-U, A. Bull, S., Greenwood, G. L., Patterson, J., Reitmeijer, C. A., Vrungos, S., ... \& O’Donnel, L. N. (2008). Safe in the city: developing an effective video-based intervention for STD clinic waiting rooms. Health Promotion Practice, 11, 408-417. 
Oyserman, D., Brickman, D., \& Rhodes, M. (2007). Racial-ethnic identity: Content and consequences for African American, Latino, and Latina youths. Contesting stereotypes and creating identities: Social categories, social identities, and educational participation, 91-114.

Oyserman, D., \& Fisher, O. (2017). Identity-based motivation and health: An identity-based motivation and social stigma approach. In: Major B, Dovidio JF, Link BG, eds. The Oxford Handbook of Discrimination, Stigma and Health, NY: Oxford University Press.

Oyserman, D., Gant, L., \& Ager, J. (1995). A socially contextualized model of African American identity: Possible selves and school persistence. Journal of Personality and Social Psychology, 69(6), 1216-1232.

Oyserman, D., \& Harrison, K. (1998). Implications of cultural context: African American identity and possible selves. In Prejudice (pp. 281-300).

Oyserman, D., \& Lewis, N. A., Jr. (2017). Seeing the destination AND the path: Using identitybased motivation to understand and reduce racial disparities in academic achievement. Social Issues and Policy Review, 11(1), 159-194.

Oyserman, D., Lewis, N. A., Jr., Yan, V. X., Fisher, O., O’Donnell, S. C., \& Horowitz, E. (2017). An identity-based motivation framework for self-regulation. Psychological Inquiry. DOI: 10.1080/1047840X.2017.1337406

Resnicow, K., Dilorio, C., \& Davis, R. (2008). Culture and the development of HIV prevention and treatment programs. Communication perspectives on HIV/AIDS for the 2st century, 193-220. 
Rimal, R. N., Lapinski, M. K., Turner, M. M., \& Smith, K. C. (2011). The Attribute-Centered Approach for Understanding Health Behaviors: Initial Ideas and Future Research Directions. Studies in Communication Science, 11(1), 15-34.

Rimal, R. N., \& Real, K. (2005). How behaviors are influenced by perceived norms: A test of the theory of normative social behavior. Communication research, 32(3), 389-414.

Simons, D. J., Shoda, Y., \& Lindsay, D. S. (2017). Constraints on Generality (COG): A Proposed Addition to All Empirical Papers. Perspectives on Psychological Science, $12(6), 1123-1128$.

Slater, M. D. (2004). Operationalizing and Analyzing Exposure: The Foundation of Media Effects Research. Journalism \& Mass Communication Quarterly, 81(1), 168-183.

U.S. Census Bureau. (2010). Census Interactive Population Search Map. 2011; Retrieved from: http://www.census.gov/2010census/popmap/

Webb, E. J., Campbell, D. T., Schwartz, R. D., \& Sechrest, L. (1966). Unobtrusive measures: Nonreactive research in the social sciences (Vol. 111). Chicago: Rand McNally. 
Figure 1: Black Patients' Attention to Health Information When Same Race Others Are

\section{Present}

\section{Black Patients' Attention to Health Information when}

Same Race Others Are Present

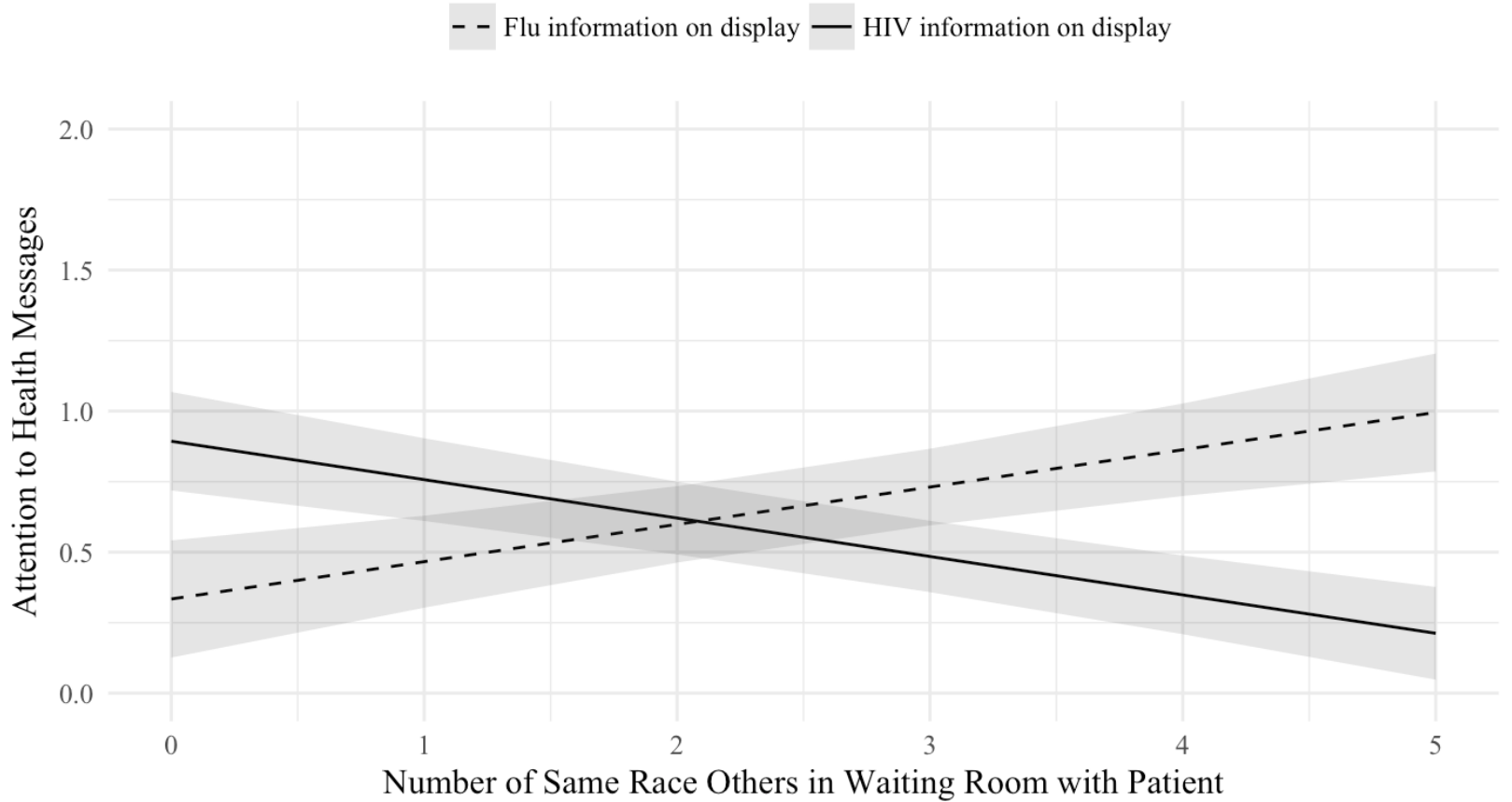

Note: Shaded region around regression lines represent one standard error of the mean. 
Figure 2: White Patients' Attention to Health Information When Same Race Others Are

\section{Present}

White Patients' Attention to Health Information when Same Race Others Are Present

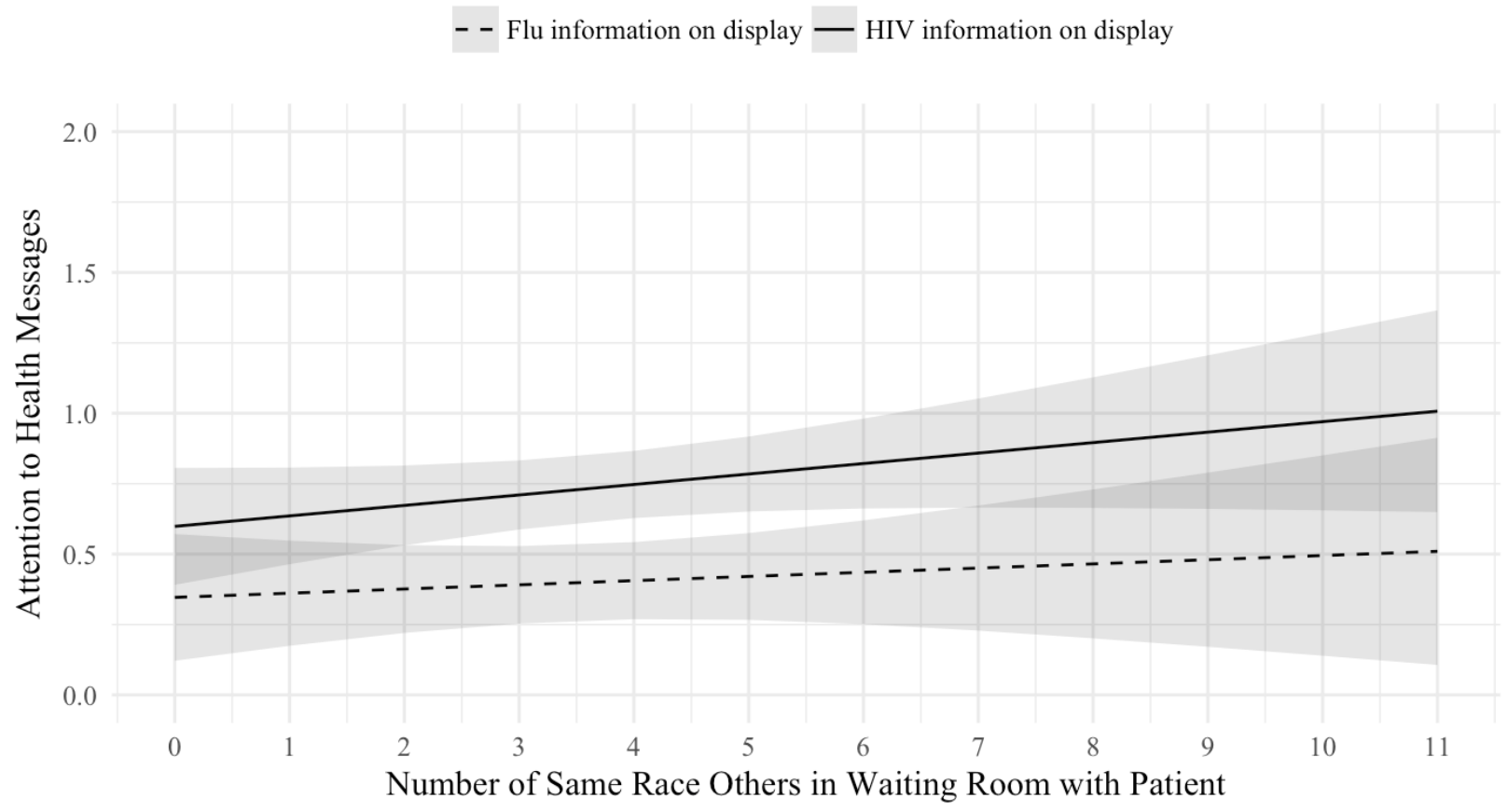

Note: Shaded region around regression lines represent one standard error of the mean. 
Figure 3: White Patients' Attention to Health Information When Other Black Patients

Ignore It

\section{Black Patients' Attention to Health Information when Other Black Patients Ignore It}

- - Flu information on display — HIV information on display

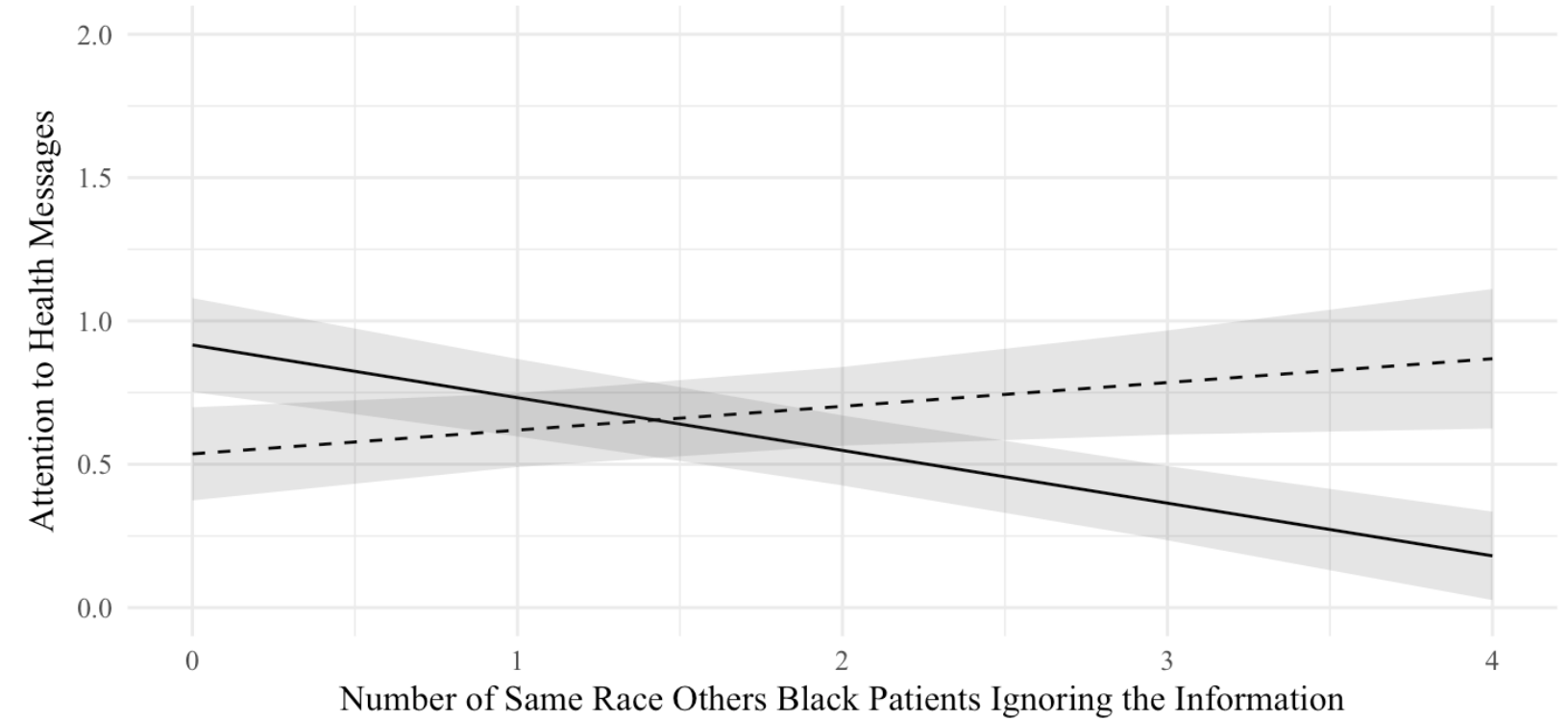

Note: Shaded region around regression lines represent one standard error of the mean 